\title{
Prevalence of obstructive sleep apnea in patients with metabolic syndrome: a hospital-based study
}

\author{
Riyaz Moideen', Uma Maheswari Krishnaswamy ${ }^{*}$, Radhika K
}

1 Department of Respiratory Medicine, M.S.Ramaiah Medical College and Hospitals, MSRIT Post, MSR Nagar, Bangalore 560054, India

2 Department of Community Medicine, M.S. Ramaiah Medical College, MSRIT Post, MSR Nagar, Bangalore 560054, India

\begin{abstract}
Background: This hospital-based study was undertaken to determine the prevalence of obstructive sleep apnea (OSA) in patients with metabolic syndrome.

Methods: Consecutive patients with metabolic syndrome were included. After relevant clinical and laboratory work-up, subjects were screened for symptoms of OSA and administered Epworth Sleepiness Scale (ESS). Patients with suggestive symptoms and ESS score of e "10 underwent polysomnography.

Results: Ninety-four patients with metabolic syndrome (53 males, 41 females) were included. Thirty-five (37.2\%) patients with high clinical probability of OSA underwent sleep study; of these, 32 had OSA. Thus, the prevalence of OSA was $34 \%$ in patients with metabolic syndrome. The values of body mass index and neck circumference were significantly higher in patients with OSA compared to those who had metabolic syndrome alone.

Conclusion: Early detection and treatment of OSA in metabolic syndrome can prevent development of systemic consequences due to the combined effect of both diseases.
\end{abstract}

Keywords: Metabolic syndrome, Obstructive sleep apnea, Syndrome Z

*Corresponding author at:

Department of Respiratory Medicine, M.S. Ramaiah Medical College and Hospitals, MSRIT Post, MSR Nagar, Bangalore 560054, India. Tel.: +918040502678,

91 9483702412; Fax: +918023601924

E-mail addresses: umamohan99@gmail.com (U.M. Krishnaswamy), riyazpmoideen@gmail.com (Riyaz Moideen), radhik121@gmail.com (Radhika K)

\section{Introduction}

$\mathrm{M}$ etabolic syndrome (MS) is a major public health challenge globally ${ }^{1}$. It was initially described as a cluster of metabolic abnormalities, with insulin resistance as the central pathophysiological feature and was labeled as 'Syndrome $\mathrm{X}^{\prime 2}$. MS is currently defined as a constellation of interrelated risk factors including hypertension, insulin resistance, dyslipidemia, and obesity. Insulin resistance and central obesity have been acknowledged as key driving forces for MS. The prevalence of MS is increasing 
due to the obesity epidemic. It is associated with a twoand three-fold increase in cardiovascular disease and type 2 diabetes mellitus, respectively. It is also associated with cardiovascular mortality as it comprises established risk factors for cardiometabolic diseases ${ }^{3}$.

There has been great interest in the interaction between obstructive sleep apnea (OSA) and metabolic dysfunction. In particular, OSA has been found to be independently associated with insulin resistance, suggesting that it may be an important factor for the development of type 2 diabetes and $\mathrm{MS}^{4}$. It has also been associated with an increased incidence of hypertension, stroke, and cardiovascular disease ${ }^{5}$. Syndrome $\mathrm{Z}$ is defined as the co-occurrence of OSA and $\mathrm{MS}^{6}$. Although there is circumstantial evidence to implicate OSA in the development of MS, the causal relationship remains unproven.

Thus, this study was undertaken to determine the prevalence of OSA in consecutive patients presenting with MS to a tertiary care hospital.

\section{Methods}

This was a hospital-based cross-sectional study conducted in adult patients with MS over a period of 18 months (November 2011 to August 2013). Institutional ethical review board clearance was obtained before commencement of the study. The inclusion and exclusion criteria are summarized next.

Inclusion criteria: Adult patients aged 18 and above fulfilling International Diabetes Federation (IDF) criteria $^{7}$ for MS (Table 1) who gave informed consent to participate in the study.

Exclusion criteria: Patients with hypothyroidism, critically ill patients, those with end-stage organ disease/ malignancy, obvious orofacial deformities, and pregnant women.

\section{Methods}

Demographic data, history, anthropometry (including body mass index (BMI), waist circumference, hip circumference), and clinical examination findings were compiled in all included patients. A blood sample $(5 \mathrm{ml})$ was drawn after $12 \mathrm{~h}$ overnight fasting for the measurement of lipid profile and fasting plasma glucose in those patients who had one or more component illnesses of MS but had not been evaluated for dysglycemia and dyslipidemia.

Patients included in the study after the above workup were screened for symptoms of OSA (snoring, witnessed apneas, and excessive daytime sleepiness). Epworth Sleepiness Scale (ESS) was used to screen for excessive daytime sleepiness. Physical examination was performed to look for upper airway anatomy (Mallampati grading was used). Patients with symptoms suggestive of OSA and an ESS score of more than 10 underwent a level 3 polysomnography (PSG). A level 3 study was conducted in view of shorter waiting times and portability compared to level 1 or level 2 PSG.

Diagnosis of OSA: The PSG data were analyzed and a diagnosis of OSA was made if the Apnea-Hypopnea Index (AHI) was $>5$ per hour. Further, severity of OSA was graded as mild (AHI 5-15/h), moderate (AHI 15$30 / \mathrm{h})$, or severe $(\mathrm{AHI}>30 / \mathrm{h})$ [8].

\subsection{Statistical analysis}

Sample size estimation: Sample size was estimated to be 85 subjects using nMaster software based on a study by Sharma et $\mathrm{al}^{9}$. with a relative precision of $10 \%$ and confidence of $95 \%$.

Analysis of data: Statistical analysis was carried out using SPSS, version 20. All the quantitative variables were summarized in terms of descriptive statistics such as mean and standard deviation or median and range. All the qualitative variables were expressed in terms of frequencies and proportions. Student's $t$-test was used to compare the difference between the mean values in OSA and non-OSA groups. $c^{2}$-Test was used to find the association between the MS components and OSA. A $p$ value $<0.05$ was considered to statistically significant.

\section{Results}

\subsection{Demographic data}

Ninety-four patients with MS were included in this study, out of which there were $53(56.4 \%)$ male and 41 (43.6\%) female. Seventy $(74.5 \%)$ patients were middle aged with a mean age of 56 years. Demographic and anthropometric parameters in the study group are depicted in Table 2. 
Table 1: International Diabetic Federation criteria for metabolic syndrome 7

Central obesity: Waist circumference $\geq 90 \mathrm{~cm}$ in men and $\geq 80 \mathrm{~cm}$ in women $\dagger$

Plus any two of the following four factors

Raised triglyceride (TG) level $(\geq 150 \mathrm{mg} /$ dl or on specific treatment)

Reduced high-density lipid (HDL) cholesterol $(<40 \mathrm{mg} /$ $d l$ or on specific treatment)

Raised arterial BP $(\mathrm{SBP} \geq 130 \mathrm{mmHg}, \mathrm{DBP} 385 \mathrm{mmHg}$ or on treatment)

Raised Fasting Blood Glucose (FBG) ( $\geq 100 \mathrm{mg} / \mathrm{dl}$ or previously diagnosed type $2 \mathrm{DM}$ )

$\dagger I D F$ cutoff values for waist circumference in Indian population.

3.2. Distribution of components of metabolic syndrome and other comorbid illnesses

Diabetes was the most prevalent component of MS with $83(88.6 \%)$ patients having the disease (Fig.1). The frequency of other components was as follows: hyperlipidemia in $67(71.3 \%)$ and hypertension in 63 $(65.1 \%)$ patients. Other major comorbidities present were ischemic heart disease (IHD) in $30(31.9 \%)$ and cerebrovascular disease in $4(4.3 \%)$ patients.

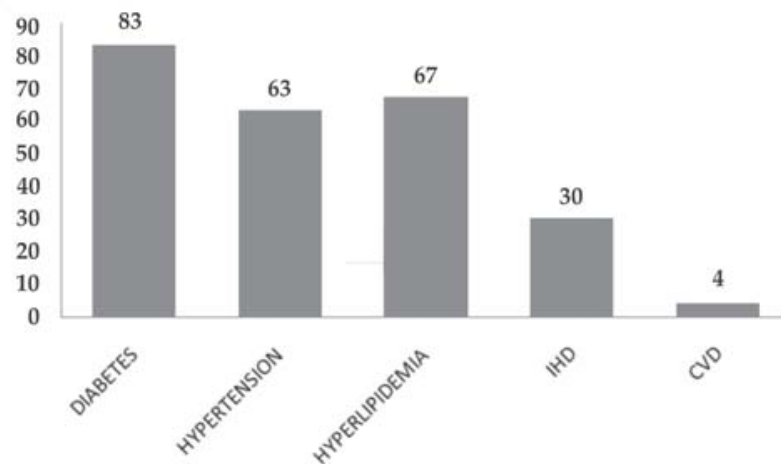

Figure 1: Components of metabolic syndrome and comorbid illnesses in the study population $(n=94)$.

\subsection{Clinical features of OSA in patients with metabolic syndrome}

The symptoms of OSA among the study group were intrusive snoring in $69(73.4 \%)$, excessive daytime sleepiness in $46(48.9 \%)$, and witnessed apneas in
Table 2: Demographic and anthropometric parameters in the study group

\begin{tabular}{|l|l|l|}
\hline Parameter & Mean \pm SD & Range \\
\hline Age (years) & $56 \pm 9.33$ & $32-78$ \\
\hline Body mass index $\left(\mathrm{kg} / \mathrm{m}^{2}\right)$ & $31.37 \pm 5.87$ & $21.9-57.6$ \\
\hline Waist circumference $(\mathrm{cm})$ & $101.21 \pm 8.87$ & $86-137$ \\
\hline Hip circumference $(\mathrm{cm})$ & $98.96 \pm 8.88$ & $82-135$ \\
\hline Waist/Hip ratio & $1.0221 \pm .047$ & $0.86-1.15$ \\
\hline Neck circumference $(\mathrm{cm})$ & $38.97 \pm 3.39$ & $32-52$ \\
\hline
\end{tabular}

16(17\%) patients. On upper airway assessment, no patients had obvious orofacial or nasal deformities whereas $6(6.4 \%)$ patients had a receding jaw. Mallampati grade of the upper airway among patients was as follows: grade 1 in $3(3.2 \%)$, grade 2 in $40(42.6 \%)$, grade 3 in $44(46.8 \%)$, and grade 4 in $7(7.4 \%)$ patients. It was found that patients with Mallampati grades 3 and 4 had higher incidence of OSA ( $45.5 \%$ and $57 \%$, respectively).

\subsection{Frequency of OSA in patients with metabolic syndrome}

Thirty-five (37\%) out of the 94 patients screened had a history suggestive of OSA and scored $>10$ on ESS. Hence, they were subjected to an overnight sleep study. Thus, there was a high pretest clinical probability of OSA in $37 \%$ of patients; however $32(91.4 \%)$ of these patients had OSA on PSG; the remaining $3(8.6 \%)$ had a normal sleep study. Thus, the frequency of OSA among the 94 patients with MS was 34\%. Nine patients each (28\%) had mild and moderate OSA whereas 14 (44\%) had severe OSA. The severity of OSA has been depicted in Fig. 2.

\section{Severity of OSA (n-32)}

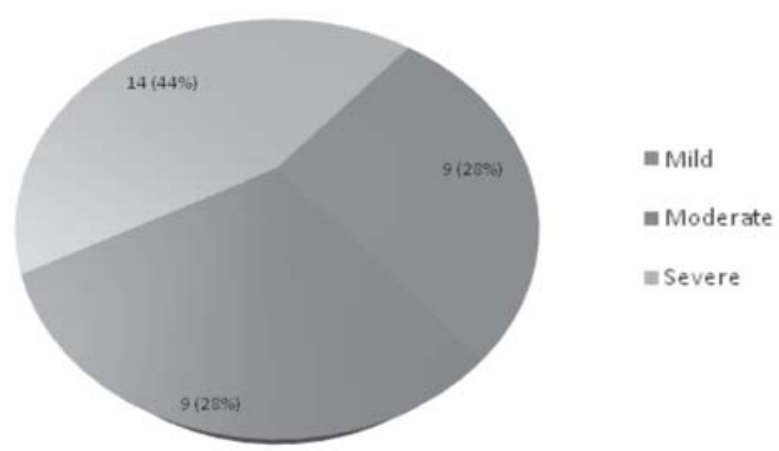

Figure 2: Severity of OSA in patients with metabolic syndrome and OSA.

Indian Journal of Sleep Medicine (IJSM), Vol. 10, No. 1, 2015 
Table 3: Components of metabolic syndrome in OSA and non-OSA patients.

\begin{tabular}{|l|l|l|l|}
\hline Parameters & OSA & Non-OSA & $p$-Value* \\
\hline Systolic BP $(\mathrm{mmHg})$ & $134.9 \pm 15.3$ & $136.41 \pm 14.9$ & 0.984 \\
\hline Diastolic BP $(\mathrm{mmHg})$ & $86.80 \pm 5.9$ & $85.56 \pm 6.3$ & 0.42 \\
\hline Waist circumference(cm) & $103.37 \pm 8.5$ & $99.93 \pm 8.9$ & 0.000 \\
\hline Diabetes mellitus $(n=83)$ & $28(33.7 \%)$ & $55(66.2 \%)$ & 0.366 \\
\hline Hypertension $(n=65)$ & $21(32.3 \%)$ & $44(67.6 \%)$ & 0.595 \\
\hline Hyperlipidemia $(n=67)$ & $24(37.3 \%)$ & $43(64.1 \%)$ & 0.679 \\
\hline
\end{tabular}

${ }^{*} p<0.05$ was considered significant.

Table 4: Frequency of OSA among subgroups of metabolic syndrome.

\begin{tabular}{|l|c|l|l|l|}
\hline Subgroups & No. of subjects, $(n=94)$ & OSA, $(n=32)$ & Non-OSA, $(n=62)$ & $p$-Value* \\
\hline $\begin{array}{l}\text { Group 1: Increased } \mathrm{WC}^{\dagger}, \mathrm{DM}^{\ddagger}, \\
\text { hypertension, hyperlipidemia }\end{array}$ & 28 & $10(35 \%)$ & $18(65 \%)$ & 0.95 \\
\hline $\begin{array}{l}\text { Group 2: Increased } \mathrm{WC}^{\dagger}, \mathrm{DM}^{\ddagger}, \\
\text { hypertension }\end{array}$ & 54 & $17(31 \%)$ & $37(69 \%)$ & 0.549 \\
\hline $\begin{array}{l}\text { Group 3: Increased } \mathrm{WC}^{\dagger}, \mathrm{DM}^{\ddagger}, \\
\text { hyperlipidemia }\end{array}$ & 56 & $20(35.7 \%)$ & $36(64.2 \%)$ & 0.79 \\
\hline $\begin{array}{l}\text { Group 4 : Increased } \mathrm{WC}^{\dagger}, \\
\text { hypertension, hyperlipidemia }\end{array}$ & 39 & $14(35.8 \%)$ & $25(64.1 \%)$ & 0.866 \\
\hline
\end{tabular}

${ }^{\dagger}$ Waist circumference, ${ }^{\ddagger}$ diabetes mellitus. ${ }^{*} p<0.05$ was considered significant.

3.5.Subgroup analysis: metabolic syndrome with and without OSA

\subsubsection{Age and gender}

Age of the study population ranged from 32 to 78 years. Mean age of patients with OSA was $56 \pm 9$ years. Four $(12.5 \%)$ patients with OSA were aged $<45$ years whereas $22(68.8 \%)$ were middle aged and 6(18.8\%) were elderly.

Eighteen out of $53(33.9 \%)$ men and 14 out of 41 $(34.1 \%)$ women had OSA. Even though the number of men was more than that of women among patients with OSA, there was no statistically significant difference in the frequency of OSA between both.

Mean BMI in patients with OSA was $34.6 \mathrm{~kg} /$ $\mathrm{m}^{2}$ whereas it was $29.5 \mathrm{~kg} / \mathrm{m}^{2}$ in those without OSA $(p<0.05)$. Neck circumference in patients with and without OSA was 41.6 and $37.4 \mathrm{~cm}$, respectively $(p<0.05)$. Thus, the values of BMI and neck circumference were significantly higher in OSA group compared with non-OSA group.

\subsubsection{Individual components of metabolic syndrome and OSA}

Further analysis was performed to compare various components of MS between patients with and without OSA, the results of which are depicted in Table 3.It was found that apart from the waist circumference, which was significantly higher in patients with OSA, there was no significant association between any other component of the MS and OSA.

\subsubsection{Frequency of OSA among subgroups of metabolic syndrome}

Patients were subgrouped according to the criteria that 
Table 5: Studies examining the association between OSA and metabolic syndrome.

\begin{tabular}{|c|c|c|c|}
\hline Reference & Design & Study population & Main results \\
\hline Coughlin et al. [10] & Case-control & $\begin{array}{l}\text { All men } 61 \text { OSA } 43 \\
\text { Controls }\end{array}$ & $\begin{array}{l}\text { Independent associations betweenOSA } \\
\text { and:MS }{ }^{\dagger} \text { (OR: 9.1), blood pressure, } \\
\text { fasting insulin, triglyceride, HDLC, TC } \\
\text { HDLC }\end{array}$ \\
\hline Gruber et al. [11] & Case-control & 38 OSA 41 Controls & $\begin{array}{l}\text { Independent association between OSA } \\
\text { and } \mathrm{MS}^{\dagger} \text { (OR: 5.9)No association } \\
\text { between OSA and insulin resistance }\end{array}$ \\
\hline Lam et al. [12] & Community based & $\begin{array}{l}255 \text { Subjects ( } 150 \\
\text { men and } 105 \text { women) }\end{array}$ & $\begin{array}{l}\text { Independent associations betweenOSA } \\
\text { and } \mathrm{MS}^{\dagger} \text { (OR: 5.3), waist } \\
\text { circumference, diastolic blood pressure, } \\
\text { fasting glucose }\end{array}$ \\
\hline Sasanabeet al. [13] & $\begin{array}{l}\text { Sleep clinic and } \\
\text { community } \\
\text { volunteers }\end{array}$ & $\begin{array}{l}819 \text { OSA ( } 719 \text { men } \\
\text { and } 100 \text { women) } \\
89 \text { Control subjects }\end{array}$ & $\begin{array}{l}\text { Independentassociation between OSA } \\
\text { and } \mathrm{MS}^{\dagger} \text { in men, but not in women }\end{array}$ \\
\hline Parish et al. [5] & $\begin{array}{l}\text { Retrospective } \\
\text { PSG and chart } \\
\text { review }\end{array}$ & 228 Patients146 OSA & $\begin{array}{l}\text { Higher prevalence of } \mathrm{MS}^{\dagger} \text { in patients } \\
\text { with OSA }(60 \% \text { vs. } 40 \%)\end{array}$ \\
\hline Sharma et al. [9] & $\begin{array}{l}\text { Community based } \\
\text { cross-sectional study }\end{array}$ & $\begin{array}{l}\text { Population of } \\
\text { South Delhi }\end{array}$ & $\begin{array}{l}\text { Prevalence of } \mathrm{MS}^{\dagger} \text { and OSA } \\
\text { (SyndromeZ): } 19.9 \%\end{array}$ \\
\hline Our study & $\begin{array}{l}\text { Cross-sectional, } \\
\text { hospital-based } \\
\text { prevalence study }\end{array}$ & $\begin{array}{l}\text { Patients with } \\
\text { metabolic syndrome } \\
(n=94)\end{array}$ & Prevalence of OSA in $\mathrm{MS}^{\dagger}$ was34\% \\
\hline
\end{tabular}

\footnotetext{
${ }^{\dagger}$ Metabolic syndrome
}

they fulfilled for diagnosis of MS. These different subgroups were compared to find if there was a predisposition to OSA with any particular combination of component diseases of MS (Table 4). Group 3 (diabetes and dyslipidemia with abdominal obesity) showed the maximum predisposition for OSA but the association was not statistically significant. Besides, there was no significant difference in severity of OSA across the groups,as shown in Fig. 3.

\subsubsection{Other comorbid illnesses and OSA}

Besides fulfilling criteria for MS, 30 (31.9\%) patients had IHD in and $4(4.2 \%)$ patients had cerebrovascular accident (CVA). Among patients with IHD, eight (26.7\%) had OSA and among those with CVA, one (25\%) had OSA. This association was not statistically significant in both subgroups.

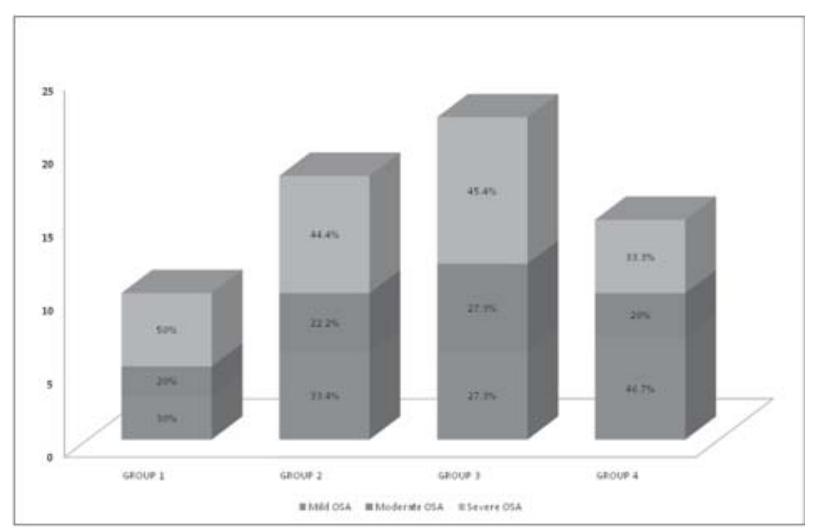

Figure 3: Severity of OSA among subgroups of metabolic syndrome.

\section{Discussion}

Our study is a hospital-based study of OSA in patients with MS; wherein nearly one-third of patients with MS 
were diagnosed to have OSA. This frequency is higher than that reported in studies conducted in the general population in Indian as well as Western literature, ${ }^{5,-13}$.

The association of OSA with various component illnesses of MS has been reported. However, literature linking MS in toto with OSA is scarce. It has been hypothesized that OSA itself may be a part of the spectrum of MS; this entity is termed as Syndrome $Z^{6}$. The results of some studies that have linked the two entities have been reviewed below. Further, the salient conclusions of these studies have been summarized in Table 5.

Coughlin et al. ${ }^{10}$ and Gruber et al. ${ }^{11}$ reported a ninefold and six-fold risk for independent association between OSA and MS, respectively ${ }^{10,11}$. Besides, the study by Coughlin et al. also concluded that the prevalence of MSwas higher in patients with OSA than that in the general population/obese non-OSA subjects.

A community-based study of Chinese subjects showed that OSA patients were at a five-fold risk of having MS. They also reported a positive correlation between $\mathrm{AHI}$ and the number of metabolic components present $^{12}$.

A case-control study in Japan by Sasanabe et $\mathrm{al}^{13}$. found an independent association between OSA and MS in men, but not in women. Cho et al14. identified associations between sleep-disordered breathing and multiple metabolic factors within the MS independent of obesity. Sharma et $\mathrm{al}^{9}$. conducted a community-based study in South Delhi and reported thatMS and OSA (syndrome Z) coexisted in 19.9\% of the study population.

In our study, nearly a third of patients had already developed systemic consequences as a result of MS. These patients could have had metabolic derangements for a longer duration and this could have perpetuated a vicious cycle wherein the occurrence and severity of OSA could have been higher than that reported in the general population. Owing to the small sample size, it was not possible to subgroup patients on the basis of duration of various components of MS and assess the odds of having OSA. However, subgroup analysis was carried out with respect to individual illnesses as well as combinations of component illnesses constituting MS, the results of which are discussed next.

Indian Journal of Sleep Medicine (IJSM), Vol. 10, No. 1, 2015

\subsection{Component diseases of metabolic syndrome in patients with OSA}

The most common component diseases of MS in our patients were diabetes mellitus, dyslipidemia, and hypertension in that order. The most common target organs damaged were the heart and brain. Further analysis was carried out to find out if there was any independent association between the earlier mentioned diseases and OSA. It was found that there was no statistically significant association between any of these diseases and OSA. In addition, it was also found that on subgrouping MS patients according to their component illnesses, there was no significant association between any particular combination of illnesses and the occurrence and severity of OSA. The literature pertaining to the association between component illnesses of MS and OSA has been reviewed next.

Ip et al ${ }^{15}$. showed higher levels of fasting blood glucose in individuals with OSA than controls. Although individuals with OSA were heavier than controls, AHI remained a significant predictor of fasting insulin levels and insulin resistance when data were controlled for adiposity. In a study of obese middle-aged adults, Vgontzas $^{16}$ found that fasting blood glucose levels were more than $20 \%$ higher in obese individuals with OSA than those in BMI-matched controls.A significant association was seen between OSA and presence of diabetes mellitus and hypertension in an urban population-based study by Udwadia et $\mathrm{al}^{17}$.

Peppard et $\mathrm{al}^{18}$. analyzed data from the Wisconsin Sleep Cohort and reported that hypertensive subjects had a higher incidence of OSA. Nieto et al., ${ }^{19}$ in the Sleep Heart Health Study showed a dose-response association between OSA at baseline and development of new onset hypertension 4 years later independent of other known risk factors.

Chou et $\mathrm{a}^{20}$. reported that among 236 patients diagnosed with OSA, the prevalence of hypercholesterolemia and hypertriglyceridemia was $61 \%$ and $55.3 \%$, respectively, and that the desaturation index was a significant independent factor contributing to hyperlipidemia in OSA.

\subsection{Demography and anthropometry of patients with OSA}

In our study, nearly three-fourths of patients with OSA were middle aged. A study by Bixler et $\mathrm{al}^{21}$. as well as the 
results of the Sleep Heart Health Study ${ }^{22}$ suggest that most of the age-related increase in prevalence of OSA occurs before age 65 years and that there is a plateau in prevalence rate thereafter. It is to be noted that both these studies were conducted in non-MS patients. The fact that our study has shown a similar trend in the prevalence of OSA even in patients with MS strengthens the hypothesis that OSA is part of the spectrum of MS.

All patients included in our study were obese and increasing grades of obesity correlated well with presence of OSA. A higher waist circumference was noted in OSA patients when compared to the non-OSA group. Similarly, there was a statistically significant increased BMI in the OSA group. This observation was in concordance with many other studies that showed that obesity is one of strongest risk factors for OSA. Some of these studies are discussed next.

In a community-based cohort of middle-aged subjects, Young et $\mathrm{a}^{23}$. showed that a $1 S \mathrm{D}$ increase in BMI was associated with a fourfold increased risk for prevalence of OSA. These researchers also showed OSA prevalence of approximately $40 \%$ and between $40 \%$ and $90 \%$ in moderately overweight and severely obese individuals. Peppard et $\mathrm{al}^{24}$. have provided further evidence for this link by showing that a $10 \%$ change in body weight was associated with a parallel change of approximately $30 \%$ in the AHI. Markers of OSA severity, such as the AHI or the degree of oxygen desaturation correlated with the amount of visceral fat in a study by Vgontzaset $\mathrm{al}^{25}$.

\subsection{Clinical features of OSA in patients with metabolic syndrome}

Snoring was the most common symptom of OSA followed by EDS and witnessed apnea in our patients. Studies have shown that habitual snoring affects up to $50 \%$ of men and up to $30 \%$ of women in the general population. According to Young et al., habitual snoring occurs in 36\% in adults and in more than $70 \%$ in subjects with an AHI $\geq 5^{22}$. Excessive daytime sleepiness and witnessed apneas were also found to be good predictors of OSA by Lavie ${ }^{26}$.

ESS was used as a screening tool in patients presenting with symptoms suggestive of OSA. Approximately one-third of patients had ESS score $>10$ with symptoms suggestive of OSA and were proven to have OSA on sleep study. A level 3 PSG was used in our study in view of a shorter waiting time and portability of the device. Although this may have resulted in an underestimation of the frequency of OSA, it was observed that more than $90 \%$ patients who had a strong history suggestive of OSA tested positive on PSG. Hence, the utility of ESS (as a screening tool for OSA) and that of a level 3 device (in patients with a high pretest probability of OSA) has been reiterated in our study. Thus, symptoms, a high index of clinical suspicion, and associated risk factors of OSA along with an ESS score of $>10$ should prompt performance of a sleep study to confirm the presence of OSA in patients with MS.

\section{Conclusions}

In our study, frequency of OSA was higher in MS patients than that reported in the general population. Although a bigger study would have enabled derivation of the odds of developing OSA with MS or vice versa, there is convincing evidence from the present study to mandate screening for undiagnosed OSA in all patients with MS.

\section{Acknowledgments}

The authors are grateful to MsVijayalakshmi $\mathrm{K}$ and MsDivya Davis scoring of sleep study data.

\section{Conflicts of interest}

All the authors of this manuscript have no conflicts of interest to disclose. This study has not received funding of any kind.

\section{References}

1. Eckel RH, Grundy SM, Zimmet PZ. The metabolic syndrome. Lancet 2005;365:1415-28.

2. Reaven G. Role of insulin resistance in human disease. Diabetes 1988;37:1595-1607.

3. Lakka HM, Laaksonen DE, Lakka TA, Niskanen LK, Kumpusalo E,Tuomilehto J, Salonen JT. The metabolic syndrome and total and cardiovascular disease mortality in middle-aged men. JAMA 2002;288:2709-16.

4. Tasali E, Ip MSM. Obstructive sleep apnea and metabolic syndrome alterations in glucose metabolism and inflammation. Proc Am Thorac Soc 2008;5:207-17.

5. Parish JM, Adam T, Facchiano L. Relationship of metabolic syndrome and obstructive sleep apnea. J Clin Sleep Med $2007 ; 3(5): 467-72$.

Indian Journal of Sleep Medicine (IJSM), Vol. 10, No. 1, 2015 
6. Sharma SK, Sreenivas V. Are metabolic syndrome, obstructive sleep apnoea and syndrome $Z$ sequential? $A$ hypothesis.Indian J Med Res 2010;131:455-8.

7. Alberti K, George MM, Zimmet P, Shaw J. The metabolic syndrome-a new worldwide definition. Lancet 2005;366(9491):1059-62.

8. Sleep-related breathing disorders in adults: recommendations for syndrome definition and measurement techniques in clinical research. The Report of an American Academy of Sleep Medicine Task Force. Sleep 1999;22(5):667-89.

9. Sharma SK, Kumpawat S, Banga A, Goel A. The prevalence and risk factors of obstructive sleep apnea syndrome in a population of New Delhi, India.Chest2006;130:149-56.

10. Coughlin SR, Mawdsley L, Mugarza JA, Calverley PM, Wilding JP. Obstructive sleep apnoea is independently associated with an increased prevalence of metabolic syndrome. Eur Heart J 2004;25:735-41.

11. Gruber A, Horwood F, Sithole J, Ali N, Idris I. Obstructive sleep apnoea is independently associated with the metabolic syndrome but not insulin resistance state. Cardiovasc Diabetol 2006;5:22.

12. Lam JCM, Lam B, Lam CL,Fong D, Wang JK, Tse HF et al. Obstructive sleep apnea and the metabolic syndrome in community-based Chinese subjects in Hong Kong. Resp Med 2006;100(6):980-7.

13. Sasanabe R, Banno K, Otake K, Hasegawa R, Usui K, Morita $\mathrm{M}$ et al. Metabolic syndrome in Japanese patients with obstructive sleep apnea syndrome. Hypertens Res 2006;29:315-22.

14. Cho N, Joo S, Kim J,Abbott RD, Kim J, Kimm K et al.Relation of habitual snoring with components of metabolic syndrome in Korean adults. Diabetes Res. ClinPract 2006;71:25663.

15. Ip MSM, Lam B, Ng MMT, Lam WK, Tsang KWT, Lam KSL. Obstructive sleep apnea is independently associated with insulin resistance. Am J Respir Crit Care Med $2002 ; 165: 670-6$.
16. Vgontzas AN. Sleep apnea and daytime sleepiness and fatigue: relation to visceral obesity, insulin resistance, and hypercytokinemia. J Clin Endocrinol Metab 2000;85(3):1151-8.

17. Udwadia ZF, Doshi AV, LonkarSG, Singh CI. Prevalence of sleep-disordered breathing and sleep apnea in middle-aged urban Indian men. Am J Respir Crit Care Med $2004 ; 169: 168-73$.

18. Peppard PE, Young T, Palta M, Skatrud J. Prospective study of disordered breathing and hypertension. N Engl J Med $2000 ; 342: 1378-84$.

19. Nieto FJ, Young TB, Lind BK, Shahar E, Samet JM, Redline $\mathrm{S}$, et al. Sleep disordered breathing and hypertension: sleep heart health study. JAMA 2000; 286:1819-26.

20. Chou YT, Chuang LP, Li HY, Fu JY, Lin SW, Yang CT et al. Hyperlipidaemia in patients with sleep-related breathing disorders: prevalence and risk factors. Indian J Med Res 2010;131:121-5.

21. Bixler E, Vgontzas A, Ten Have T, Tyson K, Kales A. Effects of age on sleep apnea in men. Am J RespirCrit Care Med $1998 ; 157: 144-8$

22. Young T, Shahar E, Nieto FJ, Redline $S$, Newman $A B$, Gottlieb DJ, et al. Predictors of sleep-disordered breathing in community dwelling adults: the Sleep Heart Health Study. Arch Intern Med 2002;162:893-900.

23. Young T, Evans L, Finn L, Palta M. Estimation of the clinically diagnosed proportion of sleep apnea syndrome in middleaged men and women. Sleep 1997;20(9):705-6.

24. Peppard PE, Young T, Palta M, Dempsey J, Skatrud J. Longitudinal study of weight change and sleep disordered breathing. JAMA 2000;284:3015-21.

25. Vgontzas AN, Bixler EO, Chrousos GP. Metabolic disturbances in obesity versus sleep apnoea: the importance of visceral obesity and insulin resistance. J Intern Med $2003 ; 254: 32-44$

26. Lavie P. Incidence of sleep apnea in a presumably healthy working population: a significant relationship with excessive daytime sleepiness. Sleep 1983;6(4):312-18. 